\title{
A Study of the Differences on Children Family Education Between China and America
}

\author{
Liu Huan \\ Chinese International Education, Xi'an Shiyou University, Xi'an, China \\ Email address: \\ 18789407845@163.com \\ To cite this article: \\ Liu Huan. A Study of the Differences on Children Family Education Between China and America. Science Journal of Education. \\ Vol. 7, No. 1, 2019, pp. 1-6. doi: 10.11648/j.sjedu.20190701.11
}

Received: January 14, 2019; Accepted: March 6, 2019; Published: March 8, 2019

\begin{abstract}
Children are the future of a country; parents are the initial and regular educators of children; and the family is the most important place for children to receive education. These all decide the importance of children family education. Nowadays, more and more countries begin to pay more attention to children education, and more and more researches are finished on this field. However, there are not enough researches on the subdivision of the family education. Based on "child-centered theory", this study uses literature analysis to explore the differences between Chinese and American children family education and find out the reasons for these differences. And the author gets enlightenment through exploring. The author finds that there are differences between China and America in educational views, educational methods, educational contents and educational results, and the reasons for differences are cultural background, social conditions and thinking patterns. The author hopes that the enlightenment of the study will be helpful to the development of children education in China and guide the young Chinese parents to educate their children better.
\end{abstract}

Keywords: Children Family Education, Educational Differences Between China and America, Educational Enlightenment

\section{Introduction}

The survey report on the current situation of children's family education guidance service issued by Chinese Children's Center [4] shows that there are many problems in children's family education in China, and more attention has been paid to children's family education. By studying the differences between Chinese and American children's family education, we can guide our young generation parents to be better qualified as "educators", pay attention to the early emotional education of children, and ensure the completeness of family education in the aspect of children's education. So that our children's education model is more perfect, our children can receive better family education. Dewey of the United States put forward the theory of "the center of children" in the mid-19th century, which holds that children are the center of education. Chen Heqin of our country put forward the early childhood education thought, thought that the child's family education is extremely important. Wang Jianbin's "Cultural differences between China and America and Children's education in China and America."[13] discusses the differences in the views on education of
Chinese and American children from three aspects: the equality of education, the way of evaluating children, and the requirements for children. However, the current research on the differences of children's education between China and the United States has been divided into the module of family education, which is not enough. This paper is based on the theory of "child-centered theory" and adopts literature analysis. To explore the following issues: first, the difference between Chinese and American children's family education; the second is the reason of these differences: the third is the enlightenment to Chinese children's family education. I hope this article can bring some enlightenment to the parents and the society and improve the children's family education in our country.

\subsection{The Significance of Children Family Education}

Children family education is the most important stage in one's education. Parents are the first and significant educators for children. Similarly, family is the initial and regular place for children to be educated. The majority of children's life habits, learning attitudes and different disposition characteristic are influenced greatly by children 
family education. In addition, good or bad habits tend to be difficult to change and even last one's lifetime. When characteristics of bad character are steadily formed, it will become accustomed to the behavior which is hard to change. So children family education plays a very important role in the process of person's education.

\subsection{The Present Situation of Children Family Education in the World}

More and more countries are aware of the importance of children family education, so they begin to care about problems of children family education. Because of the different educational views, methods, contents and so on, children family education in the world is greatly different. More and more countries are aware of the significance of children family education. Our country, China, has done lot of research on children family education. Quite evidently, China lags behind America in children family education. This backward phenomenon is not only reflected in the present situation of children family education, but also the focus of educational views. The author's study aims at finding out better methods of improving the quality of children family education in China.

\section{Theoretical Basis}

\subsection{Definitions}

\subsubsection{The Definition of Family Education}

What is the meaning of family education? It has two meanings, which can be defined as narrowed meaning and widened meaning. Its widened meaning is that mutual education among family members. In this sense, family education includes all forms of educations which come from family members. However, its narrowed meaning is more generally accepted. It means that elders especially parents educate their children in family life. About what family education is, some statements about traditional concept of family education will be made and the family education theory will be introduced. They are as follows.

i. The traditional concept of family education.

What is traditional concept of family education? It means that concept of family education in traditional culture. People often talk about a person's upbringing which depends on his family education. And upbringing mainly refers to the education of morality and politeness in traditional culture. So traditional concept of family education means upbringing. We can interpret it more specifically. It means that "Parents educate children to be a polite and moral person by the guidance of children's daily behavior" [1]. This interpretation is very realistic. And we need to learn about the theory about family education to better understand it.

ii. The family education theory by Chen Heqin.

Chen Heqin is a great educator in the history of Chinese education. He believes that "Early children family education has a bearing on the development of one's life; parents should fully develop the deep meaning of family education"
[1]. So he defines family education as "Family education is a society use to educate new generations with aims and systems" [3]. From his viewpoint, we know that he gives family education a new concept. Family education is not only related to the education of individual family, but also to society. Parents should get rid of the bondage of individual family and set up a great educational view of educating children for our country. He puts forward a series of theories about family education. Such as "Family education must be done according to children's psychology, if you do not understand children's psychology, it is useless education" [2]. His family education thoughts actually refer to children family education. Then the author will talk about what children family education is.

\subsubsection{The Definition of Children Family Education}

Before talking about the definition of children family education, the author wants to point out the period of childhood. Studies have shown that childhood refers to the period in which the child is 6 to 12 years old, the golden stage of one's growing life. So children family education refers to the family education of the child at this specific period. But there are two definitions of children family education. The difference is the definition of childhood. One refers to child who is 0 to 12 years old; the other refers to child who is 6 to 12 years old. The former classifies early childhood education into children education. In fact, the author agrees with the latter. Next, the author will introduce the traditional concept of children family education specifically.

i. Traditional concept of children family education.

What is traditional concept of children family education? It means that concept of the family education of the child who is 6 to 12 years old. It is a branch of family education; they have something in common, such as educational goals and so on. Parents educate children in childhood by all kinds of ways. "They want their child to be a man who learns excellently and has good moral characters" [1]. So the traditional concept of children family education, specifically, is that parents educate children in childhood to forming a good breeding which includes good behavior habits. And we need to learn about the theory about family education to better understand it.

ii. The children family education theory by John Dewey.

John Dewey is a great educator in the history of children education. He comes up with child-centered theory. It refers to "Shifting the focus of education from teachers and textbooks to children, a new education which is a child-centered education" [10]. He believes that "The educated individual is the social person and the society is the organic combination of many individuals. If the individual factor is taken away from the children, we are the lifeless group" [10]. He devotes his whole life to children education. His children education theory guides our children family education practice and makes people understand the importance of children family education. People are paying more and more attention to children family education. So 
there are some relevant studies about children family education at home and abroad.

\subsection{Relevant Studies}

\subsubsection{A Survey from Chinese Children's Center at Home}

This is a study [4] about the present situation of children family education in China. The content of the study is mainly to put forward scientific suggestions on the problems existing in children family education. Chinese Children's Center has found that problems through a questionnaire survey. There are some problems in the development of guidance service work of children family education, for instance, problem of guidance contents and so on. They advise that firstly we should attach importance to guidance service work of children family education, and secondly relevant policies should be introduced to support it. From this study, we can know that our country is paying more and more attention to children family education and taking positive measures to improve it. In the same way, there is also a study from abroad.

\subsubsection{A Comparative Study at Abroad}

This comparative study about the differences on present situation of children family education between China and America is valuable. The content of the study is mainly to make comparisons to get good enlightenment which can improve children family education in our country. The study shows that Americans attach great importance to children family education and pay more attention to the training of children's independent personality. But Chinese do not; instead, they develop children who are habitually dependent. So we should find out the reasons for different situation of children family education. Next, the author will introduce differences on children family education between China and America in detail.

\section{Differences}

\subsection{Different Educational Views}

Educational views are a category of conception which exists in educators' brains to guiding educational behavior, including educational ideas and evaluation criterion for education. Educational views can direct human behavior towards education. As the political theory points out, correct consciousness can promote the development of things, correct educational views also can improve educational standards. Different regions have different educational views, so the author will explain different children family educational views in China and America respectively.

\subsubsection{Chinese Children Family Educational Views}

The author expounds on Chinese children family educational views in two aspects, educational ideas and evaluation method for education. For educational ideas, Chinese parents want their children to be excellent people who can bring prestige and honor to their families and clansmen. In other words, Chinese parents want their children to have decent work, lots of money and high standard of living.

As for evaluation method for education, it mainly refers to that method for the evaluation of children's behavior. And "In China, praise and criticism are common educational tools used by parents to evaluate children's behavior. For example, they often use small red flags, snacks or toys to encourage children to compete and find out child who behaves well. This is not good for growing of children; it is easy to cause the psychology of comparison" [13].

\subsubsection{American Children Family Educational Views}

Similarly, the author also expounds on American children family educational views in two aspects, educational ideas and evaluation method for education. For educational ideas, American children family educational views mainly take Dewey's child-centered theory as the main view. Dewey believes that "Education should be based on the nature of children and education should take children as the main educational body, children family education aims at the development and growing of every child" [5]. American parents want their children to be an independent and happy man who is full of imagination and creativity.

Evaluation method for children education means the method for the evaluation of children's behavior. "American parents pay more attention to children's feelings in various activities, so evaluation of children's behavior in doing somethings is feeling. Praise is the regularly evaluation method, parents rarely teach their children critically" [5]. American parents evaluate children's behavior usually by encouraging and approving. Different educational views decide different educational methods. Next, American and Chinese children family educational methods will be introduced specifically.

\subsection{Different Methods}

\subsubsection{Chinese Children Family Educational Methods}

"A survey revealed that most of Chinese students are familiar with Chinese children family educational methods and have a lot idea to express" [17]. "In China, indoctrination in education plays important roles and less consideration is given to the development of characteristics and interests of children. Besides, directional education is also a common method. Children only learn what their parents specify" [12]. When Chinese students were young, the educational method their parents used was mainly punishment, parents believed that physical punishment was useful and parents ignored the encouragement of children's good grades. Nowadays, more Chinese parents keep inculcating in their children the truth of good grades. They always sermonize and impose their thoughts on children. They make choices for their children and deprive children's right to choose, children can only do what parents decide to do. Next, American children family educational methods will be introduced.

\subsubsection{American Children Family Educational Methods}

American adopts permeable education and "Parents pay 
attention to the loose way to educate their children, parents and children are friends. They often encourage children, no physical punishment" [12]. American parents educate their children to get truth by letting children experience themselves. They object to preaching. In addition, "Most American parents do not formally educate their children specifically in anything but to provide them with background information allowing them to choose" [6]. American children can decide on their own, their parents do not impose their thoughts. Different educational methods are embodied in different educational contents. Next, different educational contents will be introduced.

\subsection{Different Contents}

\subsubsection{Chinese Children Family Educational Contents}

Chinese children family educational contents can be divided into two parts, scores and moral education. Chinese students know the importance of score. "In China, education aims to build an educational system with more study, high score and less thought. Chinese students are generally regarded as common with high score and few intelligence" [14]. From this, it is not hard to find out that the importance of score. Examination-oriented education which centered on scores plays an important role in Chinese education. So Chinese parents attach great importance to children's score. "Chinese parents teach children to learn textbook knowledge and let children do lots of homework to get high scores. But, parents neglect children's ability of practice and innovative" [12]. Besides, Chinese parents pay more attention to moral education. "In China, parents teach children should appreciate the good qualities and understand bad qualities by giving examples, and parents often tell children the truth from their perspective" [9].

\subsubsection{American Children Family Educational Contents}

American children family educational contents are very different from Chinese. "The American children family educational contents are abundant, which mainly focus on the harmonious development of children's abilities in language, cognition, emotion, physical strength, social skills" [8]. Besides, American parents pay more attention to fostering children's ability to be independent. Moral education is an important part in American children family educational contents. American parents educate children without giving example; they educate children by giving children chance to get moral knowledge in real life. For example, American parents let children view memorial hall instead of telling stories simply.

\subsection{Different Results}

\subsubsection{Chinese Children Family Educational Result}

Educational contents decide educational results, or products. I have to say that Chinese education has produced lots of outstanding talents. But, Chinese students lack ability of living independently compared with American. Because Chinese parents often prepare everything for children and help make choices, Chinese students "Lack independent thought and they are highly dependent, passive and timid" [16]. Nowadays, there are often news reports that college students cannot take care of themselves without parents' care and even some students need parents to take care of themselves in college, such as washing clothes and so on.

\subsubsection{American Children Family Educational Result}

American parents who are usually regarded as enlightened parents. They give children more freedoms and chances to gain experience of growth. American children have a strong ability to live independently. Besides, American parents encourage children to seek adventure, and lots of children begin to travel around the world as a solo adventure. "American parents educate children to be independent and children can make choices by themselves. Children acquire life skills in real life, parents do not help take care of children" [16]. American parents want their children to be person who can live independently and own their minds. Compared with Chinese, American children are more relaxed and self-reliant.

\section{Reasons for Differences}

\subsection{Different Cultural Backgrounds}

Different cultural backgrounds can be introduced from two aspects. The one is different value orientation; the other is different cultural psychologies. This section will talk about the two differences specifically. Next, different value orientations will be mentioned.

\subsubsection{Different Value Orientations}

Different countries have different cultures that decide value orientations. So value orientations of children family education are different in different countries. In China, traditional Chinese people believe in the unity of man and nature, in fact, it refers to holism. For example, Chinese parents often tell children to have a sense of collective honor and tell children to make contributions to society and family. "Chinese tradition has always attached importance to human relation and collectivism. The meaning of life is that obedience to the collectivism and dedicate to the collective goals consciously" [13]. Guided by the value, Chinese parents have to impose high demands on children, so children have motive force to study well.

Instead, individualism plays important role in American children family education. "Individualism is the core of American culture and the premise of politics and life. It refers to the respect for individual, the belief in the individual and the emphasis on the supremacy of the individual's rights" [12]. American parents respect children's decision without interference. It is well known that American children can take drugs, drink alcohol and smoke. American children can do what they want and get the support of parents. They like to show themselves and so they have a unique personality. Of course, cultural backgrounds are not only including value orientations but also cultural psychologies. So, different cultural psychologies will be mentioned in the next part. 


\subsubsection{Different Cultural Psychologies}

Different cultural psychologies reflect on education, which makes the children family education between China and America appear obvious differences. "Comparing with American, the Chinese people like a peaceful life" [15]. Chinese are used to be satisfied with current situation, and Chinese are afraid of changing. They are always looking for stability. "Obstruction of new curriculum reform in China reflects the cultural psychology of conformism. Outdated curriculum content reflects the inflexible basic knowledge" [10]. Compared with China, American is liberated, they love new things and dare to take risks and innovate. "Reform is the theme of American education. The cultural psychology of seeking change makes American education reform constantly" [10]. American is convinced that change pushes society forward. Of course, different social conditions are also factors that we have to consider.

\subsection{Different Social Conditions}

To some extent, different social conditions affect the formation of different educational views. Here, social conditions include two parts, one is social systems, and the other is economic conditions. As far as the social system is concerned, China is socialist country and a more family-oriented nature. Socialist ideas emphasize collective interests. So, Chinese parents want their children to be talented people for families and society. America is a capitalist country and American has religious belief generally. Capitalism emphasizes personal interests. So, American parents want their children to be independent people. "The main spirit of American society is personal achievement" [6].

Economic conditions are also totally different. China is a developing country with large population, and its economy is lagging behind that of the America. So, Chinese old-age security and medical security systems are not perfect. Chinese parents need to consider more about their children's jobs that are connected with the rest of parents' living and children's future. Therefore, Chinese parents often pay more attention to children's grades which can decide whether children get a good job or not. On the contrary, America is a developed country with a small population. The superior economic conditions of America determine the perfect social old-age security system and the medical security system. American parents do not need their children to study hard to having a good job. They can spend the rest of their lives in nursing homes with the government's support. American children family education pays more attention to children's independent personality. Besides, different thinking patterns are also the important factor.

\subsection{Different Thinking Patterns}

"Chinese are good at intuitive thinking and they grasp the essence of things from the whole, from the connection, from the dynamic function" [10]. Compared with China, American pays more attention to training children to think analytically. The different thinking patterns between China and America make the children family education between China and America very different. These differences are reflected in two aspects. One is learning methods, the other is educational research. In the aspect of learning methods, Chinese emphasize self-reflection and self-examination, and Chinese regard these as ways to acquire knowledge. Instead, American emphasizes the acquisition of knowledge by observing, experimenting, measuring and so on. Educational research in China attaches importance to subjective nature and ignores objective demonstration. But American pays more attention to objective demonstration. So, different thinking patterns affect different education.

\section{Enlightenment on Chinese Children Family Education}

\subsection{Enlightenment to Chinese Parents}

From the comparison of the differences in children family education between China and America, the author gives Chinese parents some enlightenment about children family education. Chinese parents can educate children better and better through studying enlightenment. First of all, Chinese parents should change educational view which only wants their children to study hard. Parents should respect children's choice and give their more freedom. Secondly, Chinese parents should change educational contents. Parents should pay more attention to the cultivation of children's ability to be independent. Children family educational contents should pay attention to the cultivation of children's own personality and ability to be independent and innovative. For instance, parents encourage children to foster their hobbies and interests. Thirdly, based on the differences between Chinese and American children family educational methods the author would like to suggest more encouragement and support, less criticism. Besides, parents should educate their children mainly not by preaching, but by using contextual teaching so that children can get experience and knowledge from real situations. Of course, relevant education department should also listen to some advice.

\subsection{Enlightenment to Chinese Children's Education Department}

Chinese Children's Education Department should adopt relevant policies to develop Chinese children education. Firstly, Chinese Children's Education

Department should attach importance on children family education and take measures to help parents educate their children. For example, local education departments organize lectures about children family education to influence parents' old educational views. Besides, education departments should face modernization and keep pace with the development of the times, and children education should be internationalized. "China and West's education can complement each other, making the development of children's education complete" [7]. So Chinese Children's 
Education Department should strengthen exchanges with foreign children education and integrate the advantages of children education in China with those in foreign country, especially America.

\section{Conclusion}

Through the author's study, it is not hard to draw a conclusion that there are obvious differences on children family education between China and America. The author finds out these differences from four aspects and these differences have three factors. As a Chinese student, the author knows that there are many deficiencies in the children family education in China. Both the educational views and educational methods need to be improved. Children family education should be reformed. In fact, a country's economy determines the direction of education and the development of economy determines the type of talents who are trained in educational institutions. Of course, with the development of Chinese economy, Chinese children family education will be improved and will be no longer devoted to educating children to find a good job with study hard. The author hopes that Chinese parents can educate children by giving them more encouragement and fostering them ability to be independent.

\section{Acknowledgements}

First of all, my deepest gratitude goes to Professor Zhang, my supervisor, for his constant encouragement and guidance. Under his careful guidance, I learn to change the title of my thesis from broad to appropriate and I learn to write the right outline by using the information that I collected. When I was writing a paper, I had problems that I could not solve; Professor Zhang was always patient in giving me guidance. And Professor Zhang recommended me to publish my paper actively.

Besides, I want to express my sincere thanks to my dear Professor Zhang who help me find out the way to look for documents. He is a person who likes to do academic research, so he is good at finding all kinds of information.

\section{References}

[1] Chen, HQ. (1925). Family education. Beijing: China Youth Publishing House.
[2] Chen, HQ. (1983). Education works of Chen Heqin. Beijing: Beijing Publishing House.

[3] Chen, HQ. (2006). Special topic of Chen Heqin's infant thought. Shanghai: East China Normal University Press.

[4] China Children's Center.(2016). An investigation report on the present situation of family education guidance service for $0-6$ year old children.

[5] Gu, HL., \& Zhou, Y. (2003). Dewey's educational subjectivity and its enlightenment. Journal of Ningbo University, (1), 25-28.

[6] Huo, C., \& Yuan, X. (2012). A comparative analysis of the differences of family education between China and America. Creative Education, 6 (12), 1322-1327.

[7] Kuang, Y. (2012). On the differences between Chinese and western child education. Overseas English, (10), 275-276.

[8] Li, D. (2016). On the differences of Chinese and American family education from a cultural perspective. Overseas English, (21), 181-182.

[9] Li, P. (2013). Study on differences of family education in America and China: From the respective of To kill a Mockingbird. Overseas English, (05), 186-187.

[10] Liu, LQ. (2005). On the differences between Chinese and American education from the perspective of cultural tradition. Journal of Fujian normal University, (5), 120-123.

[11] Li, W. (2010). The enlightenment of Dewey's child center theory to personalized education. Science Education, (4), 92-93.

[12] Wang, XD. (2006). The comparison between Chinese and American children's educational models and their integration. Educational inquiry, (1), 34-36.

[13] Wang, JB. (2009). Cultural differences between China and America and Children's education in China and America. Social Science Review, (6), 131-133.

[14] Yang, T. (2011). The difference of elementary education between America and China. Overseas English, (10), 394-395.

[15] Zhang, Y. (2014). Comparison between Chinese and American infant family education. Learning Weekly, (31), 74-7.

[16] Zhang, YM. (2011). Causes and countermeasures of family education difference between China and America. Journal of Mudanjiang University, (7), 109-110.

[17] Zhang, C., \& Xiong, X. (2018). The causes and enlightenment of the differences in family Education between China and America. Contemporary Educational Research and Teaching Practice, (2), 87-90. 